\title{
Analysis of the Rhetorical Patterns in Iraqi EFL Students' Writings
}

\author{
Lina Lafta Jassim \\ English of Department, College of Art, University of Thi-Qar, Iraq \\ Email: Ifnar83@gmail.com
}

\begin{abstract}
This study attempts to describe and analyze how the rhetorical patterns are employed by Iraqi EFL students. The research materials are descriptive essays gather from 100 students at fourthyear. The Ninety-six samples are selected and given a quantitative analysis to compute the overall frequency of the occurrence of different rhetoric patterns. The purpose of the study is to investigate which rhetoric patterns employ most frequently in writing of Iraqi students. They are two hypotheses. First, deductive patterns are employed most frequently more than inductive ones in writing of the Iraqi EFL student. Second, most students tend to place a thesis in the first sentence of the introduction paragraph. The results of the study indicate that students preferred the deductive rhetoric pattern of inductive rhetoric patterns in their English writings. The present study can assist instructors of writing to explore the rhetoric features revealed in Iraqi EFL students' writings.
\end{abstract}

Keywords: Rhetoric patterns, inductive, reductive, topic sentence

\section{Introduction}

We can recognize the effect of different cultural and linguistic traditions (Silva: 1992:59). The main task of contrastive rhetoric researchers is distinguishing the similarities and differences for different languages. Kaplan's (1966:39) indicated: the distinctive features between different languages and rhetoric patterns. English writers prefer logical argument. However, EFL students had difficulty following a coherent structure due to the distinct difference between the direct linear structure of English writing style and the spiraling pattern of their own language rhetoric.

These contrastive rhetoricians have identified the possible causes of the apparently different organizational patterns in ESL texts as either linguistic or cultural. Under the influence of the SapirWhorf hypothesis of linguistic relativity which suggests that different languages affect perception and thought in different ways. Kaplan (1968:32) seems to hold the view that a writing pattern reflects a thinking pattern which in turn is affected by the language that one speaks as their mother tongue. Still more (Matalene, 1985; Scollon, 1991; Shen, 1989) attribute the organizational structures to the cultural background of the writer.

\subsection{Paragraph Development in English Writing}

According to Wu \& Rubins' (2000), the placement of thesis statement can be used as a guideline in determining rhetoric features and the development of paragraph as well. Similarly, Kaplan (1966:59) distinguishes English paragraph by identifying the placement of the topic statement. One common type of development usually begins with a thesis statement and followed by a series of subdivisions of that topic. The other is the reverse procedure, which states a series of examples and then relates the examples of a central statement at the end of the paragraph. The former type represents the deductive reasoning while the latter stands for inductive reasoning. Likewise, Cahill (2003:179) defines a deductive essay as "support plus concluding thesis". Therefore, the placement of the thesis statement could be adopted as a means to identify the paragraph development of essay (For more details, see the following two sections). 


\subsection{Deductive Pattern}

In English written communication, the paragraph starts with a topic statement and then to develop that statement by providing examples and explanations. The main idea is the main death with all ideas in the whole essay. That is why it is a good piece of information. A deductive of writing is considered to be unified, with no superfluous pattern of topic introduction gives the main point first and then develops the argument by providing details and reasons (Hinds, 1990). The most important information is given afterward. This is the pattern provided upfront, supporting preferred by Anglo-Americans in speaking and writing: tell others the main point first, and then add the relevant supporting details (Chien, 2007).

\subsection{The Inductive Pattern}

An inductive pattern of topic introduction refers to the message structure of putting supporting details or reasons first before the main point (Spencer et al, 2008). The goal of a text is to announce truth and arrange the argument such that it can be easily and harmoniously agreed upon by referring to communal, traditional wisdom.EFL students need to "humble" themselves of the introduction of the text. Thus, students may suggest or infer rather than state directly, since to express a point of view overtly is seen as too individualistic. They may avoid a direct statement of the thesis in the opening sections of text. The thesis is mentioned towards the middle of the text, towards the end, or perhaps never clearly at all.

\subsection{Analysis of English Discourse Organization}

The thesis statement should provide the stance, the belief or the point of view; or it states the purpose of the essay and conveys the central or main idea of the text (Yang\& Cahill, 2008:49). A descriptive essay is a wide-spread type that is intended to describe an object, an even, or a person. Descriptive usually follows the introduction-body-conclusion structure. It's important to descriptive writing to include interesting facts in the introduction part so that the reader will continue reading the paper. According to many writing guidelines and textbooks, three placements of thesis statement in descriptive essays is suggested. First, a thesis statement is suggested to be included somewhere in the introduction part in order to identify thing or person discussed in the following paragraphs. Second, the introduction should work from general to specific ending with a thesis sentence. Third, Norquist (1987) indicates that descriptive writing should begin with a topics sentence that identifies the event or person, and explain its significance later on.

Similarly, Oshima \& Hogue (2007) declare the topic sentence of a descriptive paragraph should name the topic. That is, a descriptive essay better starts with a clear identification of the topic the writer is going to describe or discuss. In conclusion, it is important to descriptive essays to include a clear topic sentence in the introduction paragraph. As to the placement of the thesis statement, one group of scholars suggested having a thesis statement at the beginning of the introduction paragraph. Those scholars declare that the topic sentence should be placed somewhere in the introduction part. Other scholars recommend a general to a specific organization and have the topic sentence appear at the end of the introduction paragraph Three types of thesis placement were found in the current research. Besides, two more different placements of the topic sentence were also investigated in students essays. Five rhetoric patterns according to the placement of the thesis statement were classified in the following chart. The first one which thesis statement appears in the beginning sentence is regarded as a Thesis in the first sentence of the beginning paragraph TFB. The second type refers to the thesis statement that is placed somewhere in the beginning paragraph (TB). The third one which places the thesis statement at the end of the introduction paragraph is classified as Thesis in the last sentence of the beginning paragraph (TLB). The forth rhetoric pattern refers to a postponed thesis statement in the second paragraph, which place the thesis statement in the middle of the essays (TM). The last type refers to those writings with a delayed thesis statement at the end of the essays (TE). The first three types, including TB, TFB, and TLB are classified as a deductive pattern. TE, which contains a delayed thesis statement, is regarded as an inductive rhetoric pattern.TM is regarded as a non-deductive and noninductive pattern. In the present essay, the rhetoric pattern was indexed by the placement of the thesis statement. When the thesis statement appeared in the first paragraph, it was regarded as a deductive 
rhetoric pattern. Similarly to the explanation given by Cahill (2003), a deductive essay means "initial thesis plus support" and an inductive essay means support plus concluding thesis" (Cahill, 2003: 179). Therefore, the thesis statement placed in the introduction paragraph, including TFB, TB, and TUB, showed a deductive pattern. Thesis-at-end (TE) pattern reflected an inductive pattern. Thesis-in-middle (TM) pattern combined both deductive and inductive patterns.

The location of the opinion-stating following four: Initial (stated in the introduction), Middle (in the middle section), Final (in the conclusion), or obscure (not clearly stated). There were no cases of more than one position taken in the same text.

\section{Methods of Investigation}

In order to achieve the aims of this study, several methods are chiefly employed as the descriptive, analytic and statistic methods. The design of the study is based on the combination of both qualitative and quantitative approaches. The qualitative approach is used in describing and analyzing data to find the frequency of deductive and inductive rhetoric types in the subjects' writings. On the contrary, the quantitative approach is used for determining the percentages of using these types in the students' writings.

\subsection{Subjects}

One hundred students' writings from English dept., College of Education for Human Sciences, University of Thi-Qar are selected randomly for gathering the data of this study. One hundred fourth years subjects are examined in terms of their placement of thesis statement, and arrangement of supporting ideas to determine deductive and inductive rhetoric pattern of students' essay.

\subsection{The Writing Task}

The title of the writing task is "My Best Friend". This topic is chosen for it is believed that writings would be easier if a given topic is most related to the subjects' life experience. That is why, the subjects are expected to express as much as possible without constraints. About sixty compositions collect from sixty subjects in class are analyzed and statistically indicated.

\subsection{The Instrument for Analyzing Rhetorical Patterns}

The current study modified the classification based on the study of Liu (2009) and Petric (2005) concerning to rhetoric pattern. Five rhetoric patterns in total according of the placement of the thesis statement were classified in table 1.

Table 1. The coding scheme of rhetoric patterns

\begin{tabular}{|c|c|}
\hline Location of thesis statement & Definition \\
\hline $\begin{array}{l}\text { 1. Thesis in the first sentence of the beginning } \\
\text { paragraph (TFB) }\end{array}$ & Topic sentence appears as the first sentence of the essay \\
\hline 2. Thesis in the beginning paragraph (TB) & $\begin{array}{l}\text { The topic sentence occurs somewhere in the introduction } \\
\text { paragraph. }\end{array}$ \\
\hline $\begin{array}{l}\text { 3. Thesis in the last sentence of the beginning } \\
\text { Paragraph (TLB) }\end{array}$ & $\begin{array}{l}\text { Topic sentence as the final sentence of the introduction } \\
\text { paragraph. }\end{array}$ \\
\hline 4. Thesis in the middle (TM) & Topic sentence was postponed in the body part of the Essay \\
\hline 5. Thesis in the end (TE) & A delayed topic sentence appears in the conclusion Paragraph \\
\hline
\end{tabular}

\subsection{Procedures of Data Collection}

Figure 1 shows the procedure of data collection. Generally speaking, the findings indicate that deductive patterns (TFB, TB, TLB) are employed most frequently, followed by non-deductive and non-inductive 
rhetoric pattern (TM).

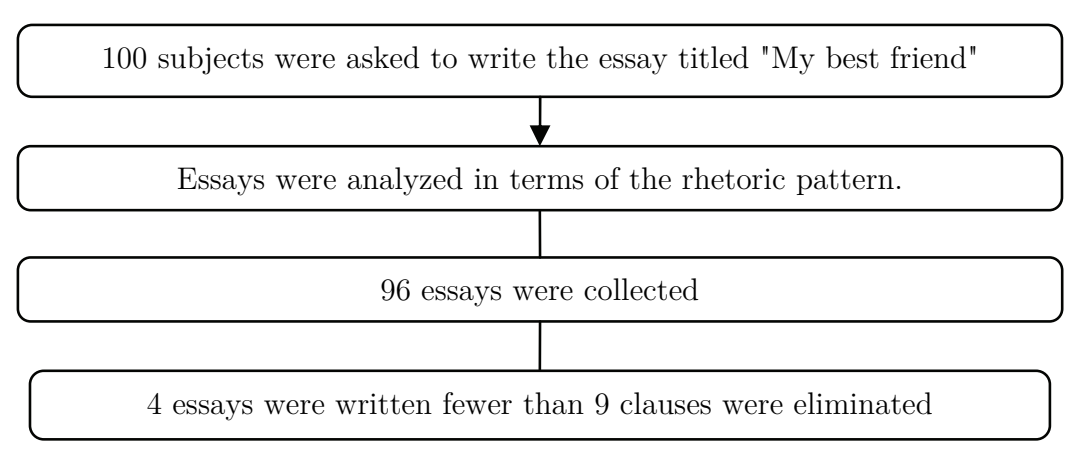

Figure 1. Procedures of data collection

\subsection{Results and Discussion}

\subsubsection{Quantitative analysis}

This section presents the overall frequency of rhetoric patterns use in students' Inductive pattern (TE) is the least rhetoric pattern. The findings above prove that the first hypothesis which is "Deductive patterns are employed most frequently than inductive ones in the Iraqi EFL students' writings" is accepted. A more detailed discussion of how the rhetoric patterns are carried out in students' writing are presented in the following section. (See table 2)

Table 2. The frequency of rhetoric patterns used in students writings

\begin{tabular}{lcc}
\hline Location of thesis statement & Total & Percentage \\
\hline 1. Thesis in the first sentence of the beginning paragraph (TFB) & 39 & 441 \\
2. Thesis in the beginning paragraph (TB) & 24 & 25 \\
3. Thesis in the last sentence of the beginning paragraph (TLB) & 7 & 7 \\
4. Thesis in the middle (TM) & 23 & 24 \\
5. Thesis in the end (TE) & 3 & 3 \\
\hline
\end{tabular}

\subsubsection{Qualitative analysis}

This section discusses five rhetoric patterns, including thesis in the first sentence of the beginning paragraph (TFB), thesis in the beginning paragraph (TBP).

\subsubsection{Thesis in the first sentence of the beginning paragraph (TFB)}

The type that thesis statement appears in the first sentence of the beginning paragraph which is also the introduction of the whole essay, was the most common type used by students .Several kinds of opening sentence were found in students' writings. Most students tend to use a direct and explicit way of opening an introduction like the following examples. The passage below is a typical type that straightly identifies the main idea of the essay.

My best friend is Talal ....... Talal is a good man. His habit is very forthright but he also impulsive. We all play basketball after school. Talal is very strong and he always wins in basketball game. (Text 1)

My best friend is books. Reading book not only increase my knowledge but also my vision.

When I was bad mood, I would read some book and forget those which made me sad and

failed.There is a saying goes, "He who makes a mistake makes nothing." By reading good books, the learned, the more I saw my ignorance. (Text 2)

The opening sentence identified a thing or person the author was going to describe in the following passages. Therefore, the opening sentence was meanwhile the thesis statement of the whole essay that conveyed the central idea of the essay. Besides the typical type such as text (1) and (2) that identified 
the main topic, other verified ways of opening an introduction were found in other students' samples, which are shown below:

Daphne Wang my best friend at senior high school, I like her because she had a kind heart to help people and she always had a good performance on her schoolwork. (text 3).

Text 3 used the person's name as the grammatical subject of the opening sentence. It was different from the previous examples that started with "my best friend ".That is, the person's name was introduced at the beginning. The name of the best friend was reinforced in the first place. The main idea was presented directly and explicitly as well.

When it comes to my best friend, she is a pretty, charming and active person. Her name is Annie, who accompanies with me and get through much difficult time in my secondary school life. I remember that out first sight was in junior cram school. Her outstanding personality appeals to me to meet her. At that time, we were just a friend, not best friend as I entered secondary school we met again and became best friend from then on. (Text4)

"When it comes to" was used a lot in student's samples. It helped the reader to grasp idea the author tried to convey in that passage.

I want to introduce one of my best friends, Hala. She is really the coolest person her, she is good at art and design. Furthermore, she is also a good photographer: She always thinks differently with others. You will amaze what she ever said and done before. (Text 5)

Some students tend to use a more colloquial way to start the topic. To write with a colloquial tone, the reader is considered as a listener. Therefore, your writing would sound more like a letter or a transcript rather than a formal writing. Like Text 5, the personal pronoun you" appeared in the last sentence (you will amaze what she ever said and done before) of the paragraph. The stance of the writing has been transferred from the person being described to the reader. The function of placing thesis statement at the beginning sentence is to identify the thing or person later illustrated as well as to help the reader to grasp the main idea as soon as possible. It was indicated that most students, 39 out of 96 , tend to place the thesis statement by the beginning of the sentence in the introduction paragraph. This proves that the second hypothesis which emphasizes that "most students tend to place thesis in the first sentence of the introduction paragraph" is true.

\subsubsection{Thesis in the beginning paragraph (TB)}

To put the thesis by the beginning paragraph, it refers to the thesis statement was placed somewhere in the beginning paragraph. Notably, it was found that students tend to put the thesis statement at the second or third sentence of the beginning paragraph. The thesis statement was placed after defining the topic or after describing the person which would be discussed later. This section presents several texts where the thesis statement was placed somewhere in the beginning paragraph.

Everyone has their friends but only one is the best friend. Of course, I have my best

friend named Julie. I met Julie for the first time, I felt she is vivid cute and optimistic. I like her and view her as my best friend, so does she. Julie does everything a gentle heart and usually gives me some dessert to thank me that I take good care of her. Although we sometimes quarrel with some trifle we will make peace with each other. Julie is good at English. in contrast. I am clever in Chemistry and Math. Therefore, we will teach others which we aren't good at. (Text 6)

Text 6 is an example of TB. The thesis statement was delivered after giving an opening statement for the topic "the best friend".

A friend can influence one person's life a lot. It is important for us to meet a good friend for our lifetime. For me, I had met my best friend of my whole life, Judy, an energetic girl who always can encourage someone else. With short hair and black skin, she looks like a born athlete who is good at any sports. I got along with her: I always can feel the energy come for her: I will never forget the day we met together. It was that we moved to the place which we live now. When I met that girl. She quickly relieved my anxieties and took me around to familiar with the new place. The girl is Judy, the first friend I met at that time and the most important friend in my life. (Text 7).

Text 7 is another type of a short opening about the significance of making good friends. 
I think that friend is essential in my life. I need a friend to help me and give me courage. My best friend is a handsome boy that everyone called him Martin. He is so perfect and popular: He is $180 \mathrm{~cm}$ but just 50 kilograms. He has blue bright eyes, white skin, straight nose, and smallmouth. No one in school ever heard about him. We often play basketball in the gym and do some interesting things our friendship is very staunch like a stone that no one can break it. (Text 8)

After presenting his point of view about friends, the writer continued to describe the feature of his own best friend.

As the proverb goes friend in need is a friend indeed." A best friend will give you a hand without hesitation on the right time, giving spiritual support for your injured heart. To answer who is my best friend, needless to say, he must be Jack. Jack, who was one of the most famous students in my class, had not only had a great sense of humor but also a thoughtful heart to those who needed help. As far as I concerned he was just like an idol for me. (Text 9)

Text 9 was a common type found in students' samples. Proverbs were mostly used as an opening statement.

By examining the texts of TB, it was found out that definition and proverbs were commonly used as an opening statement to introduce the following person they were going to discuss. Therefore, a slight difference between TFB and TBs was in the opening statement that employed in TB. That is FB cut into topic straightly and directly while TB indirectly introduces the main idea. Many students employed TB in their writings (25 out of 96). It can be related to the studies that indicate the preference of using proverbs in EFL students' writings According to Matalene (1985), EFL students rely on the fixed patterns such as proverbs and idioms. The writers are encouraged to incorporate poems and proverbs in their writings (Wu and Robin, 2000:67) in order to achieve social harmony. Chen (1994) claims the usage of proverbs is rewarded for increasing the beauty of language. EFL students prefer using proverbial reference in their own language and English writings. Wong (1992) found that the participants referred to their proverbs frequently in their own language as well as in English. Therefore, using proverbs or general definitions in Iraqi EFL students ' writing as the opening statement is similar to Arabic writings.

\subsubsection{Thesis in the last sentence of the beginning paragraph (TLB)}

The last type of deductive rhetoric pattern is to postpone thesis statement at the end of the beginning paragraph. As supported by some scholars, a general to specific introduction is preferred in descriptive essays. That is, the introduction should be ended with a thesis sentence. It is pretty similar to the following texts.

He has a strong personality. He can bring many laughs to our classroom. He is a pistacha nut. In the class, he can the boring class be more interesting. In the time he comfort the bad mood friend to make his sadness go away. He is my best friend, Jalaal. (Text 10)

In Text10, several sentences were employed to describe the best friend before the author turning to the thesis statement.

I will never forget such a valuable experience happening to me at a secondary school. No matter when I recall this unforgettable experience, I still feel embarrassed and cannot help but burst into crying and sorrowful. The memory has remained in my mind because of his handsome face. Talal whose nickname is Tooli is my best friend in my life. (Text 11).

Sometimes experience or a story between the author and the best friend were started before the thesis statement is delivered.

Few students employed TLB organization. only 7 out of 96 samples used TLB which is organized in two identical orders. One is to put a description of the person before the main idea. The other is to firstly elaborate on the process of how the author and the best friend become friends.

TFB, TB and TLB are different in the placement introduction paragraph, All in all, these three patterns are still considered as a deductive organization. That is, the thesis statement is stated in the early stage, and followed by detailed supporting ideas of the later paragraphs. 


\subsubsection{Thesis in the middle (TM)}

TM is the type that cannot be classified as a deductive or inductive pattern since the thesis statement is placed in between. It is noteworthy that many students, 24 out of 96, like to postpone their thesis statement of the second paragraph.

Examples are shown below:

Needless to say: people can without Friend" means the people who can let you open your mind and talk everything to him or her since we began to in kindergarten, we might play with many children. Until you become younger, you may find that only few people can share your happiness and sorrow and to solve any problem. Those people are called "best friends."

One of my best friends is called Raji. Eason, is not the student get good grades in the exam or the most popular guy in our class. Eason is a drawer and an artist, whom many people always tell him to be realistic. But in my he the only one person who told me to face my life optimistic It was a story: a student who always has a bad temper so 1 often quarrel with other. One day, I fought with my classmates again for using my pen without my permission. As soon as started to shout at him. Raji touched my shoulder and told me Look before you leap, try to think you angry when you recall this thing after ten years. "Suddenly: I realized how silly Raji became my best friend. His personality can stand my temper when getting angry and complained to him. Sometimes I would protect him when some people laugh his dream. (Text 12)

In the beginning paragraph in Text 12, the definition of "the best friend" occurred at the beginning paragraph, similar to TB. We discussed earlier, the definition of "best friend" was served as an opening statement. The difference lies in the development of the subtopic. That is. TB treats the short opening statement as a sub-theme that can be related to the main theme late on whereas TM tends to develop the sub-theme into a full length.

It was in the cram school that I first saw her. We only had seen each other several times without any interaction. As time went by, we entered the same senior high school unexpectedly Much to our surprise, when we talked to each other at the first time, we knew that we were in the same class.

After entering the same class we became friends. We accompanied each other to go to the bathroom, chatted about this and that and went shopping together However we never told each other everything in our deep hearts. Even she encountered some obstacles that we became "best friends."

As far as I am concerned, she is an essential member of my life. we told each other everything, help each other get over the depression. share our happiness together. She is as generous that she can endure some weakness for mine. One thing is for sure that we have many similar personalities. For example, both of us are pessimistic and sentimental. Because of these reasons, we became best friend undoubtedly and villas our friendship forever. (Text 14)

Another type of TM appeared at the middle of the second paragraph, Text 14, for example, described how they met each other. However, the main theme of the essay appeared at the final sentence of the second paragraph, followed by the third paragraph illustrating why they became best friends. The writer used many sentences to develop the procedure of becoming best friends. However, the second part of the essay focused on elaborating the significance of the best friend.

People benefit from friends a lot. People can share the joy or sadness. They get assistance when they need. Almost everyone has friends in this life.

I have a lot of friends. All of them are kind to me. However, no matter how well the relationship between two guys, there sometimes has some quarrels would happen. But to me, I have a best friend and special friend who had never been or showed a bad temper for me. Although he is just passed away when I was ten. he would still live in my mind and would be accompanied with me toward the unknown future. He was my dog-Jacob. (Text 15)

Text 15 is also another example of TM. It stated the definition of "the friend" in the paragraph. The second paragraph was related to the topic of the writer himself, followed by a transition and then turning to the topic sentence. Chou (1989:78) proposed two alternative procedures for the development of EFL students' rhetoric patterns. One procedure is that introducing the main theme develops the main theme, provide anecdote example, and conclude. The other procedure is to disguise the main theme with 
a sub-theme, develop the subtheme, introduce the main theme and conclude. It is interesting to note that the TM is consistent with the second procedure of essay development. That is, the main theme is introduced until the subtheme is well developed. The examples presented in this section were all featured by the development of sub-theme. Hence the main idea was postponed to the second paragraph. Based on the theoretical background, the delay of the main theme is probably influenced by the Arabic rhetoric pattern.

\subsubsection{Thesis in the end (TE)}

$\mathrm{TE}$ is a special rhetoric pattern found in students samples. The thesis statement is postponed in the final paragraph. A delayed thesis statement refers to a more inductive style of rhetoric. That is, many supporting ideas are given earlier than approaching a thesis or theme. Only three out of 96 in the current study used this pattern. The following are the detailed discussion of the rhetoric pattern.

She is a graceful girl and knows lots of things what she learns from the extra study. She doesn't like to talk in public, but she can easily express her thought in logic and always be trusted by others. The most special temperament she interests me is the always viewpoint she has to her life. Every time when I was in the bad mood she not only gives me a warm hug or listen what make me being upset but cheer me up by sharing some optimistic idea that always enlarges my eyesight seeing the life, the world we live.

To my surprise, in my memory, we don't have any quarrels with each other. We always have the opposite thoughts but we will try to understand what the other thing, we share our idea and find creation in our conversation. Both of us learn a lot from each other: In the special day like birthday, we write long letters to each other to appreciate that we can have such a great friendship.

She is my best friend because I know she knows me, will give me a hand when I need someone to accompany. we have each other and most important is we know to give others enough space. She is my best friend. (Text 16)

Text 16 was noteworthy that it started without any topic sentence that could clearly identify what was been talking about. The first and second paragraph failed to directly relate the title with its text. A clear and direct relevance to the title "my best friend" was given at the final paragraph. A delayed thesis statement was hard for the reader to figure out the focus of the writing without knowing the title. That is, it was at the last paragraph that the author's best friend was identified.

I used to be alone when I was in secondary school shy and quiet then so I didn't have any friend Until one day; she came to me. Her name is Hadeel. She is a very outgoing and energetic girl our first conversation is unforgettable. she said "hi, my name is Hadeel. Since this moment you are my friend" I burst out laughing as soon as she finished what was going to say she laughed at me. too since then, no matter where we went or what we did we always be together shared out little secrets each other had something would cheer us up.

Time passed so quickly, three years in secondary were about to finish. Bath of us ware very sad to say goodbye We will always be in touch our friendship would last forever. Hadeel will be my best friend forever. (Text 17)

Text 17 was a similar to the previous one. The paragraph started with a description of the person without relating to the topic of the writing. The distinctive feature of TE is that a clear relevance to the topic is placed in the final paragraph. Consequently, the reader would be confused if the title has not been given in the first place.

My best friend can't talk but it can make me warm every day except a rainy day or cloudy: Sometimes feel bad and want to cry, it always gives me some power. Then feel better and smile again and encouragement best friend is shining every day. Its body has seven kinds of colors. In fact, can't see it at night because it's another friend will come out. That is to say: that or bed at night When I get up and go to school. it follows me and smiles to me.

Many people's friends can talk, opinion. it's ok because we talk every time and everywhere by using our mind I think using our mind to talk to each other is better than using mouth. My best friend gives some posers to realize my dream. (Text 18)

The last TE sample was rather interesting. The writer first elaborated many features for her best friend. In the end, she asked the reader to guess the best friend she referred to. Namely, the whole essay was like a puzzle which is comprised by many hints about the best friend, and the answer was given at 
the end of the essay. Thus, TE is a special pattern found in student's essay. TE, meanwhile, is an inductive rhetoric pattern which postpones thesis statement till the last paragraph.

\section{Pedagogical Implications}

The findings in the current study have some direct implication for EFL/ESL writing instructions. In EFL teaching, it is common that English composition is taught based on sentence-level accuracy (Yao, 1989:33). Grammatical accuracy plays a significant role in the grading criterion of good English writing. One suggestion of the study is that EFL teachers should pay attention to the distinctive feature of students' writings. As presented in the findings, some students tend to start the writing with an introduction while an important thesis statement is left behind. Being aware of the rhetoric features of students' writings, teachers will be able to help students be aware of the different conventions preferred by L1 and L2 students. For example, Arabic rhetoric values proverbs in wirings while English rhetoric regards proverbs as cliché. By investigating the distinctive features of student's writings, teachers can detect the preferred pattern employed by students so as to guide them with proper instruction. Furthermore, Raimes (1999) proposed five principles to improve writing pedagogy concerning contrastive rhetoric studies. One of the principles is the recognition of students' diversity. Namely, every student is different. Teachers need to realize that not all approach and procedures satisfy students. The emphasis on complexity of composition and diversity of students makes it imperative for researchers and educators not to seek a universal prescription of language teaching. Another principle is the recognition of learners' process. Raimes (1999:61) noted that language teachers need to know about the process of how students learn a language and how writers construct a writing product. Since students' approaches to writing in English are undoubtedly shaped by their educational backgrounds and rhetoric patterns (Spack, 1997:772), teachers should take learners' process in learning and writing into account when applying to teaching. Therefore, teachers need to be aware of students writing process and products in order to design a writing approach that most satisfy the students.

\section{Conclusion}

The purpose of the present study is to examine the rhetorical pattern preferred by Iraqi EFL students. By examining the writing samples, deductive pattern occur frequently in samples. That is, students prefer to introduce thesis statement in early stage. Very few samples include the inductive pattern. In addition, the percentage of samples using TM is almost equal to that of samples using TB. It is found that students tend to start writing with a brief opening statement. Proverbs and definitions are found majority employed as an opening statement. The current study indicated that the students tend to use active rhetoric pattern in descriptive writings. That is, the main theme of the essay is often illustrated in the early stage of the essay.

\section{References}

1. Cahill, D. (2003). The Myth of the "Turn" in Contrastive Rhetoric. Writing Communication, 20(2), 170-194. Ulla.

2. Chien, C.S (2007). The Role of Chinese EFL learners' Rhetorical Strategy Use in Relation to their Achievement in English Writing. NewYork: Cambridge University Press. Vol.(6) No.(1), 132-150.

3. Chou H L. (1989). Contrastive Rhetoric: Chinese and English. In S. M. Chang, D. S. Tseng, \& B. C. Hwang (Eds.), Collection of Papers Presented in the Sixth Conference on English Teaching and Learning in the Republic of China. (PP.251-269). Taipei, Taiwan: Crane.

4. Connor. U. (1996). Cross Cultural Aspects of Second Language Writing. Cambridge: University Press.

5. Hinds, J. (1990). Inductive, Deductive Expository Writing in quasi-inductive: Chinese and Thai. In U. Connor\& A. Johns (Eds.). Coherence in Writing: Research and pedagogical perspectives (pp. 87-110). Alexandria, VA: TESOL.

6. Kaplan, R. (1966). Cultural Thought Patterns in Intercultural Education. Language Learning, 16, 1-20.

7. Liu (2009). Intercultural Rhetorical Pattern Differences in English Argumentative Writing. Journal of English as an International Language, 4, 93-109 
8. Malatlene ,C.(1985) Contrastive Rhetoric :An American Writing Teacher in China. College English,47(8),789228.

9. Nordquis,R.(1987).Passsages:A Writer's Guide .New York:St.Martin Press.

10. Oshima, A. \& Hogue, A. (1997). Introduction to Academic Writing (2ed.) London. Longman.

11. Petric, B. (2005). Contrastive Rhetoric in the Writing Classroom: A Case Study. English for Specific Purposes. $24,213-228$

12. Raimes,A.(1991). Out of the woods: Emerging Traditions in the teaching of Writing. TESOL Quarterly, 25(3), 407-430.

13. Richards. J. et al. (1985). Longman dictionary of applied linguistics. London Longman.

14. Silva, T. (1992). LI vs. L2 Writing: ESL Graduate Students' Perceptions. TESL Canada journal, 100, 27-48

15. Spack,R.(1997).The Rhetorical Construction of Multilingual Students. TESOL Quarterly, 31,765-774.

16. Spencer, Wang \& Xing. (2008). Raising Students' Awareness of Cross-Cultural Contrastive Rhetoric in English Writing via an e-Learning Course. Language Learning Technology. 12(2), 71-93

17. Wong, S. D. (1992). Contrastive Rhetoric: An Exploration of Proverbial References in Chinese L1 and L2 Writing. Journal of Intensive English Studies, 6, 71-90.

18. Wu, Y \& Rubin, D. L. (2000). Evaluating the Impact of Collectivism and Writing by Chinese and North American College Individualism on Argumentative. Research in the Teaching of English, 3512), 148-178.

19. Yang L., \& Cahill, D. (2008). The Rhetorical Organization of Chinese and American Students' Expository Essays: A Contrastive Rhetoric Study. International Journal of English Studies, 8(2), 113-132.

20. Yao, L. C.(1989). An Overview of Instructional in Taiwan. Taichung, Taiwan: Chung Hsing University. 